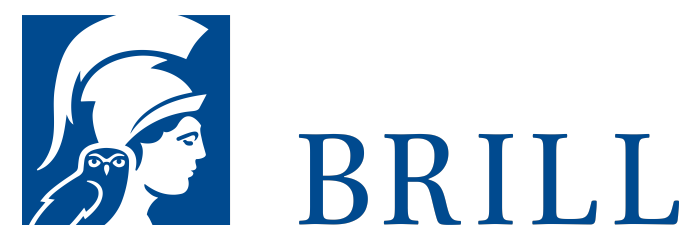

\title{
Evolution - Kognition - Dichtung
}

Zur Anthropologie der Literatur

Author: Karl Eibl

Die Literaturwissenschaft widmet sich seit einigen Jahren verstärkt dem Zusammenhang von Kognition und Dichtung. Dass die menschliche Kognition ihrerseits im Rahmen der biologischen Evolution zu betrachten ist, ist in den kognitivistischen Literaturstudien weniger präsent. Karl Eibl hat sich diesem Defizit bereits 2004 in seinem Buch Animal poeta zugewandt, indem er die anthropologischen Grundlagen aus den neueren Entwicklungen in Soziobiologie und Evolutionärer Psychologie für einen literaturwissenschaftlichen Erkenntnisbedarf adaptierte und weiterentwickelte. Nach einer Folgestudie zum biologischen Kulturbegriff, die 2009 unter dem Titel Kultur als Zwischenwelt erschien, wendet Eibl sich mit diesem Buch nun spezifischer literarischen Phänomenen zu. Der einleitende Teil des Buches rekapituliert die Rahmentheorien für eine biologische Perspektive auf Sprache, Kultur und Ästhetik. In mehreren Kapiteln zu literarischen Formen und Figuren werden dann grundlegende Strukturphänomene erörtert, die sich aus biologisch verankerten Dispositionen ableiten lassen. So wird anschaulich gemacht, wie aus dem induktiven Erfahrungslernen die Möglichkeit zu metaphorischer Bildlichkeit hervorgeht und wie sich universale Plots auf kognitive Gestalterwartungen zurückführen lassen. Auch die Autorposition wird aus biologischer Perspektive betrachtet und als notwendige Instanz im...

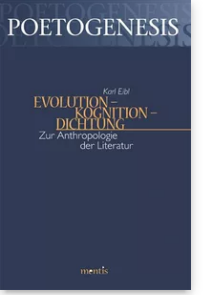

Pages: 284

Seiten

Language:

German

Subjects:

German,

Literature and

Cultural Studies

Publisher: Brill | mentis

Series:

Poetogenesis -

Studien zur empirischen

Anthropologie

der Literatur,

Volume: 9

E-Book (PDF)

Released online:

1o Feb 2016

ISBN: 978-3-

95743-863-8

List price

Paperback

Publication date: 10 Feb 2016

ISBN: 978-3-

95743-047-2

List price 
For more information see brill.com

Order information: Order online at brill.com +44330 333 0049 | customerservices@brill.com Submission information: brill.com/authors

Titles published by Brill | Fink, Brill | mentis or Brill | Schöningh: +49(o)715413279216| brill@brocom.de 